Original Article (short paper)

\title{
Effects of additional external load manipulation on perceptual and physiological responses during exergame
}

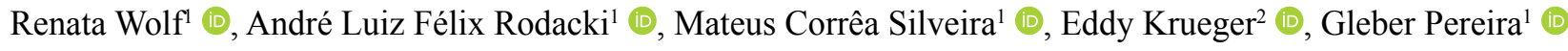 \\ ${ }^{1}$ Universidade Federal do Paraná, UFPR, Department of Physical Education, Curitiba, PR, Brazil; ${ }^{2}$ Universidade \\ Estadual de Londrina, UEL, Neural Engineering and Rehabilitation Laboratory, Londrina, PR, Brazil
}

\begin{abstract}
Aims: This study tested whether performing exergames with and without additional external load could induce to different internal load demand for young adults. Methods: Fifteen young women $(24.4 \pm 4.06$ years) participated in the study. Electromyography (EMG) activity, heart rate (HR) and overall and local rating of perceived exertion (RPE) were determined in "Just Dance" and "Ski" exergames without additional external load and with additional external load of 5\% of body mass attached bilaterally to the ankles in "Just Dance" and using a weight vest in "Ski". Results: EMG, HR and overall RPE presented similar responses between loads in both exergames ( $>$ >.05). However, local RPE differentiate internal load only in "Just Dance", with higher values with additional load (with additional load: $11.2 \pm 2.1$ RPE; without additional load: $10.3 \pm 1.4 \mathrm{RPE} ; \mathrm{p}=.037$ ). Conclusion: Therefore, performing exergames with an additional external load of $5 \%$ of young women body mass did not induce different internal load demand in "Just Dance" and "Ski" exergames compared to performing such games without external load. However, the greater local RPE in "Just Dance" exergame after adding the external load suggests that a higher amount of load (i.e., $>5 \%$ of body mass) to this population may generate different internal load demand.
\end{abstract}

Keywords: external load; perceptual responses; physiological responses.

\section{Introduction}

Physical training with exergames has been suggested as an alternative exercise routine due to the enjoyment of individuals while exercising, leading to an increase of acute energy expenditure ${ }^{1}$ and improvement on the aerobic fitness ${ }^{2,3}$, balance ${ }^{4}$ and muscle strength of the lower limbs ${ }^{5}$. The energy expenditure is increased with exergame compared to sedentary condition and the intensity of an exergame session - measured with heart rate (HR) and rating of perceived exertion (RPE) - is moderate in young women ${ }^{6}$; however, higher intensities (i.e., internal and external load) during the exergame training session may play a key role in the success of physiological enhancements.

Indeed, the exercise intensity manipulation is mandatory in training prescription to achieve health promotion ${ }^{7}$. However, the exercise intensity in exergames has been usually manipulated by the game level/difficulty ${ }^{4,8}$ and such a manipulation may not necessarily induce to higher physical effort levels. Thus, wearing additional loads - a classical strategy to increase the load in several sport training routines - without changing the exergame characteristics, may be an alternative to manipulate exercise intensity. The use of additional external loads may induce to higher neuromuscular (electromyography - EMG), cardiovascular (HR) and perception of effort (RPE) demands, leading to an increase of exercise intensity to comply with the American College of Sports Medicine (ACSM) recommendations for health promotion.

During exercise, it is important to identify how much a muscle is required through its activation level, which is a key point for the training program ${ }^{9}$. Muscle activation, measured by EMG, may vary according to the specific requirements of the task including dynamic vs. isometric muscle contraction mode ${ }^{10,11}$, fast vs. slow movement speed and other demands, e.g., force and internal torques $^{12}$. Indeed, a faster movement speed during swimming exergame has induced greater EMG activity ${ }^{13}$. Thus, wearing additional load while playing different exergames (e.g., dancing and skiing) may present a singular demand that allows one to increase the muscle activity.

The RPE has been able to identify exercise intensity differences amongst exergames and traditional exercises, such as walking and cycling ${ }^{14,15}$. This is possible because RPE is based on the internal load of individuals perceiving an exercise, being congruent with the external load performed. Although the RPE is correlated with physiological parameters (e.g. HR and EMG) during exercises with an incremental load in cycling ${ }^{16,17}$ and running ${ }^{18}$, these results do not follow the same pattern during continuous load exercises. For instance, 30 minutes of circuit-training at fixed HR induced RPE increase throughout the exercise ${ }^{19}$. This inconsistency between HR stabilization and RPE increase is due to the perception of the internal load being greater as the exercise progresses, despite the maintenance of the external load ${ }^{15}$. Then, the no-correlation between HR and RPE in exercises with external load maintenance suggests that RPE is generated independently from HR response ${ }^{20,21}$. Hence, the RPE may be able to differentiate exercise intensity during different exergames that maintain external load constant during a session, although the HR may not change throughout the session. 
The exergame is a pleasurable physical activity, with high levels of enjoyment in all ages ${ }^{22}$. Then, the combination pleasurable physical activity and external load increment may improve the level of physical activity in young women - since this population practice less regular physical activity than young men $^{23}$ - and increase the physical gains due to adequate overload progression. Therefore, the purpose of this study was to check if performing exergames with and without additional external load induces to a different internal load demand. It was hypothesized that EMG, HR, and RPE would be greater in exergame played with an additional external load than without load.

\section{Methods}

Fifteen young women $(24.4 \pm 4.06$ years-old; $63.41 \pm$ $8.07 \mathrm{~kg} ; 169.6 \pm 6.08 \mathrm{~cm})$ volunteered to participate in the study and provided their written informed consent prior to experimental procedures. All participants were free from known musculoskeletal or neuromuscular disorders that could influence the results and were deemed in good health conditions by a physician. All procedures were approved by the University Ethics Committee (1.990.679).

\section{Exergame session}

Participants visited once the laboratory and played two games ("Just Dance" and "Ski") with two different intensities (with and without an additional load). The game "Just Dance" (song "Problem" - by Ariana Grande), contains repeated movements of lower limbs, including squats and hip flexion, while "Ski", requires sustaining a squat position and some small jumps from this position as part of the interactive demand of the game (XBOX $360^{\circledR}$, Kinect). In the "Just Dance" exergame, the additional load was attached bilaterally to the ankle, as exercise demand increase due to hip and knee extension and flexion movements during the dance. In the "Ski" exergame, participants had a weight vest firmly attached to the trunk as this game requires isometric muscle contractions and squat jumps. The additional load wearing (i.e., ankle or trunk) was based on a pilot study, as the weight vest interfered with upper limbs movements while dancing and the load attached to the ankle did not improve participants' internal load due to isometric muscle contractions in skiing. For both exergames, the additional load was set to correspond to $5 \%$ of the body mass of each participant. Such a percentage was based on a pilot study, in which higher overload decreased the quality of movements required by the exergame.

At the first part of the session ( $\sim 15-20$ minutes), participants were familiarized with the games and data collection procedures. Familiarization lasted until the dance routine had been fully learned, and the jumps had been given at the right time in the "Ski" game. Then, 10 minutes resting interval was allowed before the exergame trials (i.e., between each time the game was played). For each trial of "Just Dance", "Ski" was played two consecutive times, to match the time played between games ( 3 minutes). The sequence of the games and the loads were randomly defined (www.randomizer.org). The EMG was measured throughout the exergame trials, whereas the HR and the RPE were measured immediately after the end of the exercise trial.

\section{Heart rate}

Heart rate was measured immediately after each exergame trial using a heart rate monitor (Polar m400, Finland). The heart rate during the exercise was calculated with respect to the percentage of maximum heart rate $\left(\mathrm{HR}_{\max }=220 \text { - age }\right)^{24}$.

\section{Rating of perceived exertion}

Perception of effort was measured using the Borg's (6-20) RPE scale at the end of the exergame trials. Before each trial, participants received instructions about how to report the RPE (overall) and the lower limbs RPE (local) $)^{25}$. In short, it was explained that: "During the exercise we want to evaluate your perceived exertion, in other words, how difficult, heavy and hard you feel the exercise. Six in the scale means "no effort" and 20 means "maximal exertion". Score nine corresponds to a "very light" exercise for a person which is like walking slowly at your own pace for a few minutes. Score thirteen is an exercise "somewhat hard", but it still feels good to keep going. Score seventeen or "very hard" is a very vigorous exercise. A person can still perform it, but he/she really has to struggle. You feel very hard and tired. Score nineteen is an "exhaustive" exercise. For most people this is the most intense workout ever experienced. Look carefully at the scale and their expressions, and then give a number. Any questions?"25.

\section{Electromyography activity}

The neuromuscular activity of the exergame session was measured by surface electromyography (EMG). The skin was shaved and cleaned before the EMG electrodes were attached on rectus femoris (RF), biceps femoris $(\mathrm{BF})$, tibialis anterior (TA) and gastrocnemius lateralis (GL) muscles of the right limb using quadripolar surface electrodes (Trigno Wireless System, Delsys $^{\mathrm{TM}}$, Boston, Massachusetts). EMG data were collected with a sampling frequency of $1 \mathrm{kHz}$. These muscles were chosen for their importance in performing the main exergame exercises (e.g. squat and dance movements $)^{26-28}$. Electrode placement followed SENIAM's guidelines ${ }^{29}$. The EMG data were acquired by Nexus 2.1.1 software. In "Just Dance", the EMG data were collected during approximately 40 seconds thereafter the song phrase "And realize that I've got". For "Ski", the data were recorded during the entire second race (beginning from the start sound until crossing the finish line: 40 seconds).

The signal processing was tested with a custom-written MatLab $^{\circledR}$ routine (MathWorks, Inc, 2013). EMG signals were filtered with a 3rd order Butterworth $20-450 \mathrm{~Hz}$ bandpass filter with notch filters on power line harmonics $(60,120,180,240,300$, 360 and $420 \mathrm{~Hz}$ ). For EMG data normalization, all participants were instructed to walk three times at their self-selected speed 
over a $10 \mathrm{~m}$ long walkway before practicing the exergames. The mean of EMG data acquired in the gait was used to calculate the root mean square (RMS) of $\mathrm{EMG}_{\mathrm{GAIT}}$ (Equation $1 ; n=$ data sample), which was applied to every muscle. Then, for each muscle $\left(\mathrm{EMG}_{\text {EXERGAME }}\right)$ the signal was rectified and divided by $\mathrm{RMS}_{\mathrm{GAIT}}$ $\left(\% \mathrm{RMS}_{\mathrm{GAIT}}\right)$, creating a normalized data $\left(\mathrm{EMG}_{\mathrm{NORM}}\right)($ Equation 2$)$.

$$
\begin{aligned}
R M S_{\text {GAIT }} & =\sqrt{\frac{1}{n} \sum_{i=1}^{n} E M G_{G A I T^{2}}} \\
E M G_{\text {NORM }} & =\frac{\left|E M G_{\text {EXERGAME }}\right|}{R M S_{\text {GAIT }}} \times 100
\end{aligned}
$$

\section{Statistical analysis}

Data normality was checked by Shapiro-Wilk test. The EMG did not present a normal distribution and was analyzed through Wilcoxon test to compare the trials with and without load. The HR and RPE were analyzed through a paired $t$-test to comparing the trials with and without load. Effect size was determined based on Cohen's $d$ calculation for paired comparisons ${ }^{30}$ with such reference values: $(\leq 0.2)$ trivial; $(>0.2)$ small; $(>0.5)$ moderate and $(>0.8)$ large effect. The significance for all tests was set at $\mathrm{p}<5 \%$ and statistical analysis was performed using the software SPSS 22.0 (Chicago, IL).

\section{Results}

The HR was similar between the load conditions in both exergames ("Just Dance", $t=-.419 ; \mathrm{p}=.682$; "Ski", $\mathrm{t}=-.109$; $\mathrm{p}=.915$ ) (Figure 1). In addition, the overall RPE was comparable and did not differ between the load conditions ("Just Dance", $\mathrm{t}=-1.824 ; \mathrm{p}=.090 ;$ "Ski", $\mathrm{t}=-.837 ; \mathrm{p}=.417$ ) (Table 1 ). The local RPE did not differ when participants wore an additional load in comparison with the unloaded condition in the "Ski" game $(\mathrm{t}=-1.703 ; \mathrm{p}=.111)$. On the other hand, local RPE was greater when an additional load was applied than without a load in the "Just Dance" game $(8.4 \% ; \mathrm{t}=-2.303 ; \mathrm{p}=.037 ; \mathrm{d}=-.45)$ (Table 1).

The EMG activity of all muscles was similar between with and without an additional load in both games (Table 2).

Figure 1. Percentage of maximal heart rate (HRmax) during Just Dance and Ski exergame with and without additional load.

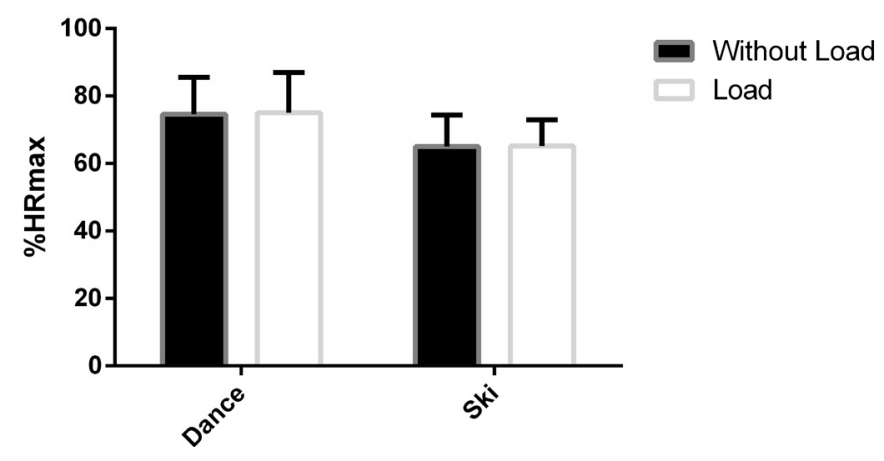

Table 1. Overall and local RPE during Just Dance and Ski exergames played with and without an additional load.

\begin{tabular}{ccccccc}
\hline & Just Dance & Just Dance + load & p & Ski & Ski + load & p \\
\hline Overall RPE & $11.7 \pm 2.3$ & $12.5 \pm 2.4$ & .090 & $11.3 \pm 2.2$ & $11.7 \pm 2.7$ & $12.5 \pm 2.2$ \\
Local RPE & $10.3 \pm 1.4$ & $11.2 \pm 2.1^{*}$ & .037 & $11.7 \pm 2$ & .111 \\
\hline
\end{tabular}

RPE: rate of perceived exertion; * Significantly different from Just Dance.

\begin{tabular}{|c|c|c|c|c|c|c|}
\hline & Just Dance & Just Dance + Load & $\mathbf{p}$ & Ski & Ski + Load & $\mathbf{p}$ \\
\hline Rectus femoris & $\begin{array}{c}432 \\
(264-650)\end{array}$ & $\begin{array}{c}392 \\
(275-695)\end{array}$ & .776 & $\begin{array}{c}445 \\
(286-614)\end{array}$ & $\begin{array}{c}490 \\
(306-627)\end{array}$ & .776 \\
\hline Biceps femoris & $\begin{array}{c}118 \\
(105-166)\end{array}$ & $\begin{array}{c}134 \\
(106-176)\end{array}$ & .496 & $\begin{array}{c}88 \\
(78-124)\end{array}$ & $\begin{array}{c}98 \\
(85-138)\end{array}$ & .496 \\
\hline Tibialis anterior & $\begin{array}{c}142 \\
(120-194)\end{array}$ & $\begin{array}{c}147 \\
(127-208)\end{array}$ & .650 & $\begin{array}{c}109 \\
(90-152)\end{array}$ & $\begin{array}{c}113 \\
(93-157)\end{array}$ & .691 \\
\hline Gastrocnemius lateralis & $\begin{array}{c}185 \\
(137-210)\end{array}$ & $\begin{array}{c}169 \\
(131-229)\end{array}$ & .570 & $\begin{array}{c}105 \\
(79-144)\end{array}$ & $\begin{array}{c}108 \\
(80-149)\end{array}$ & .191 \\
\hline
\end{tabular}

Table 2. Neuromuscular activity during Just Dance and Ski exergames with and without an additional load.

All data are expressed in percentage of the walking trial. Data are presented as median and interquartile interval. 


\section{Discussion}

This study aimed to check whether performing exergames with and without an additional external load induces to different internal load demand in young women. The moderate exercise intensity was characterized by RPE and HR measurements, agreeing with previous study ${ }^{6}$. However, using an external load did not change the internal load in both games, although such approach can be a promising way of manipulating exercise intensity, as the local RPE was greater with an additional load than without a load in the "Just Dance" game.

The addition of an external load in the "Just Dance" and "Ski" games was not sufficient to change EMG activity. The low muscle activation level in the "Ski" game performed without an additional external load may be explained by the type of the contraction, as most of the game was performed isometrically ${ }^{10,11}$. The "Just Dance" game performed without additional external load presented low muscle activation due to the place that the external load was attached (ankle). This may have not imposed a high resistance to the lower limbs, which was similar to walking in a self-selected pace. A previous study that manipulated the intensity of the swimming exergame using faster movements ${ }^{13}$ was successful to produce higher EMG activity. The EMG activity differences between studies (additional load vs faster movements) may be explained by the low neuromuscular demand imposed by the external load (5\% of participant's body mass), despite the place that it was worn. Thus, the low muscle activation levels in both games are not challenging to young women, irrespective of the use of an external load of $5 \%$ body mass.

The heart rate measures were also not able to identify differences while exercising with and without an external load in both games. Probably the external load was not sufficient to impose a higher cardiovascular system demand in comparison to the unloaded condition. However, the local RPE was able to identify differences in internal load in "Just Dance" game, whereas the overall RPE was similar between the load conditions. It has been suggested that RPE is generated independently of physiological responses ${ }^{20}$, especially in continuous exercises ${ }^{19}$, because the external load is maintained, while the internal load is perceived to increase by the individual. Moreover, the load attached bilaterally to the ankle may have emphasized the lower limb efforts, i.e., a local exercise. Thus, a weight vest with a higher external load may eliminate the local exercise characteristic and it may be a promising strategy to increase the internal load. In addition, wearing a weight vest may be safer since it does not involve an external load to the ankle that may cause a trip during exercise.

There are some limitations to the current study. First, the participation of only young women compromises the extrapolation of the results to young adults' population. Second, the external load (5\% of body mass) was not able to increase the exergame intensity from moderate to vigorous, irrespective of the variable applied to determine the internal load. The use of a larger external load should be tested to determine its greater efficiency for such purpose. The use of an additional external load may constitute a promising way to manipulate and enhance the internal load in exergame training not only for young adults but also for older adults since it is important to prescribe a training program with an ideal intensity to improve intrinsic parameters related to physical health.

Therefore, performing exergames with an additional load did not induce to different internal load demands in young women in comparison to performing such games without a load. The greater local RPE in the "Just Dance" game suggests that a higher amount of load (i.e., $>5 \%$ of body mass) is required in order to increase the internal load demands.

\section{References}

1. Simons M, Brug J, Chinapaw MJM, Boer MD. Replacing NonActive Video Gaming by Active Video Gaming to Prevent Excessive Weight Gain in Adolescents. PLoS One. 2015;10(7):1-21. http:// dx.doi.org/10.1371/journal.pone.0126023

2. Thin AG, Hansen L, Mceachen D. Flow Experience and Mood States While Playing Body Movement-Controlled Video Games. Games Cult. 2011;6(5):414-428. http://dx.doi. org/10.1177/1555412011402677

3. Naugle KE, Naugle KM, Wikstrom EA. Cardiovascular and Affective Outcomes of Active Gaming: Using the Nintenso Wii as a Cardiovascular Training Tool. J. Strength Cond. Res. 2016;28(2):443451. http://dx.doi.org/10.1519/JSC.0b013e31829999c3

4. Vernadakis N, Derri V, Tsitskari E, Antoniou P. The effect of Xbox Kinect intervention on balance ability for previously injured young competitive male athlete : A preliminary study. Phys. Ther. Sport. 2014;15:148-155. http://dx.doi.org/10.1016/j.ptsp.2013.08.004

5. Siriphorn A, Chamonchat D. Wii balance board exercise improves balance and lower limb muscle strength of overweight young adults. J. Phys. Ther. Sci. 2015;27:41-46.

6. Viana RB, Alves CL, Vieira CA, Vancini RL, Campos MH, Gentil $\mathrm{P}$, et al. Anxiolytic Effects of a Single Session of the Exergame Zumba ${ }^{\circledR}$ Fitness on Healthy Young Women. Games Health J. 2017;6(6):1-6. http://dx.doi.org/10.1089/g4h.2017.0085

7. Pescatello RS, Arena R, Riebe D, Thompson PD. ACSM'S Guidelines for Exercise Testing and Prescription - Ninth Edition. The Journal of the Canadian Chiropractic Association. 2014;58(3):328. http:// dx.doi.org/10.1017/CBO9781107415324.004

8. Young W, Ferguson S, Brault S, Craig C. Assessing and training standing balance in older adult : A novel approach using the " Nintendo Wii ' Balance Board. Gait Posture. 2011;33:303-305. http://dx.doi.org/10.1016/j.gaitpost.2010.10.089

9. Fenwick CMJ, Brown SHM, McGill SM. Comparison of Different Wowing Exercises: Trunk Muscle activation and Lumbar Spine Motion, Load, and Stiffness. J. Strength Cond. Res. 2009;23(5):14081417. http://dx.doi.org/10.1519/JSC.0b013e3181b07334

10. Tax AAM, van der Gon JJ, Erkelens CJ. Differences in coordination of elbow flexor muscles in force tasks and in movement tasks. Exp. brain Res. 1990;81:567-572.

11. Theeuwen M, Gielen CCAM, Miller LE. The relative activation of muscles during isometric contractions and low-velocity movements against a load. Exp. brain Res.1994;101:493-505.

12. Bijker KE, de Groot G, Hollander AP. Differences in leg muscle activity during running and cycling in humans. Eur. J. Appl. Physiol. 2002;87:556-561. http://dx.doi.org/10.1007/s00421-002-0663-8 
13. Soltani P, Figueiredo P, Fernandes RJ, Vilas-Boas JP. Muscle activation behavior in a swimming exergame: Differences by experience and gaming velocity. Physiol. Behav. 2017;181:23-28. http://dx.doi. org/10.1016/j.physbeh.2017.09.001

14. Kraft JA, Russell WD, Bowman TA, Selsor III CW, Foster G. Heart rate and perceived exertion during self-selected intensities for exergaming compared to traditional exercise in college-age participants. J. Strength Cond. Res. 2011;25(6):1736-1742. http:// dx.doi.org/10.1519/JSC.0b013e3181e06f13

15. Perron RM, Graham CA, Hall EE. Comparison of Physiological and Psychological Responses to Exergaming and Treadmill Walking in Healthy Adults. GAMES Heal. J. Res. Dev. Clin. Appl. 2012;1(6):411-415. https://doi.org/10.1089/g4h.2012.0050

16. 16. Borg G, Hassmén P, Lagerström M. Perceived exertion related to heart rate and blood lactate during arm and leg exercise. Eur. J. Appl. Physiol. Occup. Physiol. 1987;56:679-685.

17. Demura S, Nagasawa Y. Relations between perceptual and physiological response during incremental exercise followed by an extended bout of submximal exerise on a cycle ergometer. Percept. Mot. Skills 2003;96:653-663.

18. Garcin M, Wolff M, Bejma T. Reliability of Rating Scales of Perceived Exertion and Heart Rate During Progressive and Maximal Constant Load Exercises Till Exhaustion in Physical Education Students. Int. J. Sports Med. 2003;24:285-290.

19. Azevedo A, de Matos LF, Nakamura FY, Pereira G. Perception of effort monitors internal load during compounded circuit training. Motriz 2016;22(1):90-93. http://dx.doi.org/10.1590/ S1980-65742016000100013

20. Marcora SM. Perception of effort during exercise is independent of afferent feedback from skeletal muscles, heart, and lungs. J. appliied Physiol. 2009;106:2060-2062. doi:10.1152/ japplphysiol.90378.2008

21. Smirmaul BPC, Dantas JL, Nakamura FY, Pereira G. The psychobiological model : a new explanation to intensity regulation and (in ) tolerance in endurance exercise. Rev. Bras. Educ. Física e Esporte 2013;27(2):333-340.

22. Graves LEF, Ridgers ND, Williams K, Stratton G, Atkinson G, Cable NT. The Physiological Cost and Enjoyment of Wii Fit in Adolescents, Young Adults, and Older Adults. J. Phys. Act. Health. 2010;7:393-401.
23. Azevedo MR, Araújo CLP, Reichert FF, Siqueira FV, da Silva MC, Hallal PC. Gender differences in leisure-time physical activity. Int. J. Public Health. 2007;52:8-15. https://doi.org/10.1007/ s00038-006-5062-1

24. Fox III SM, Naughton JP. Physical Activity and the Prevention of Coronary Heart Disease. Prev. Med. (Baltim). 1972;120:92-120.

25. Borg G. Borg's perceived exertion and pain scales. Human Kinetics, 1998.

26. Caterisano A, Moss RF, Pellinger TK, Woodruff K, Lewis VC, Booth W, et al. The effect of back squat depth on the EMG activity of 4 superficial hip and thigh muscles. J. Strength Cond. Res. 2002;16(3):428-432.

27. Trepman E, Gellman RE, Solomon R, Murthy KR, Micheli LJ, de Luca CJ. Electromyographic analysis of satanding posture and demi-plié in ballet and modern dancers. Med. Sci. Sports Exerc. 1993;26(6):771-782.

28. Schaub PA, Worrel TW. EMG activity of six muscles and VM0:VL ratio determination during a maximal squat exercise. J. Sport Rehabil. 1995;4:195-202.

29. Konrad P. The ABC of EMG. A pratical introduction to kinesiological electromyography. 2005;1:30-35.

30. Nakagawa S, Cuthill IC. Effect size, confidence interval and statistical significance : a practical guide for biologists. Biol. Rev. 2007;82:591-605. doi:10.1111/j.1469-185X.2007.00027.x

\section{Corresponding Author}

Renata Wolf

Mailing address: Rua Coração de Maria, 92, BR 116, Km 95, Jardim Botânico, Curitiba, Paraná, Brasil

E-mail: renata.wolf@gmail.com

Manuscript received on May 3, 2018

Manuscript accepted on August 28, 2018

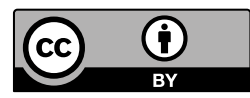

Motriz. The Journal of Physical Education. UNESP. Rio Claro, SP, Brazil - eISSN: 1980-6574 - under a license Creative Commons - Version 3.0 